A teoria versus a prática e as novas Diretrizes

Curriculares Nacionais no ensino do

\author{
fotojornalismo

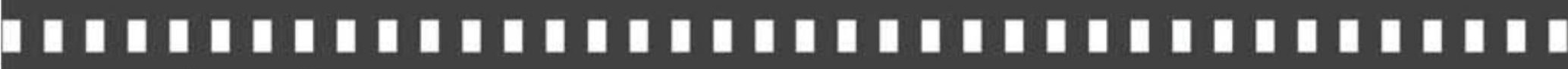

\author{
Dayana Estevam Moreira \\ Glaucia da Silva Brito
}

Artigo recebido em: 27/01/2019

Artigo aprovado em: 02/10/2020 


\title{
A teoria versus a prática e as novas Diretrizes Curriculares Nacionais no ensino do fotojornalismo
}

\author{
Theory versus practice and the new \\ National Curriculum Guidelines in teaching photojournalism
}

\author{
Dayana Estevam Moreira* \\ Glaucia da Silva Brito**
}

Resumo: Este artigo é resumo da dissertação de mestrado, cujo objetivo foi responder à pergunta: de que modo os professores de fotojornalismo percebem as novas Diretrizes Curriculares Nacionais? Identificar possiveis barreiras para o equilibrio entre teoria e prática no ensino da disciplina e pensar as novas diretrizes como aliadas para a transposição destas, foram passos da pesquisa. Percebeu-se que, apesar de haver dificuldades, os docentes preocupam-se constantemente com o equilibrio entre teoria e prática no ensino da disciplina.

Palavras-chave: Teoria e prática. Currículo. Jornalismo. Fotojornalismo.

\begin{abstract}
This article is a summary of a Master Thesis whose the main purpose was to answer the question: how do photojournalism teachers perceive the new National Curricular Guidelines? Identifying potential barriers to a balance that exists between theory and practice when teaching the discipline and thinking new guidelines as allies for the transposition of these, were some of the steps of this research. It was noticed that, although there are difficulties, teachers are constantly concerned with the balance between theory and practice when teaching the discipline.
\end{abstract}

\footnotetext{
* Mestre em Comunicação pela Universidade Federal do Paraná (UFPR).

** Doutora em Linguística pela Universidade Federal de Santa Catarina (UFSC). Professora do Programa de Pós-Graduação em Educação da Universidade Federal do Paraná (UFPR).
} 
Keywords: Theory and practice. Curriculum. Journalism. Photojournalism.

\section{Introdução}

Desde a sua implantação no Brasil, até hoje, o ensino da Comunicação Social foi regido por cinco Currículos Mínimos e por Leis de Diretrizes e Bases, passando por reestruturações diversas nos cursos, ora engessando a criação do currículo pleno com a exigência de conteúdos fixados nos currículos mínimos, ora flexibilizado com diretrizes curriculares. As diretrizes, apesar de possibilitarem uma formação que valorizasse questões regionais - dada a grandiosidade do país -, também davam margem para interpretação abusiva por parte das universidades, que poderiam instituir como currículo pleno o que bem entendessem.

A experiência vivida durante o meu curso de Comunicação Social com habilitação em Jornalismo e a notícia de uma nova mudança nas diretrizes do ensino superior gerou uma reflexão a respeito do equilíbrio entre a teoria e a prática dentro de disciplinas que, por natureza, exigem atividades de campo, como o fotojornalismo. As aulas aconteciam em um ambiente com estrutura adequada, em um período da educação cujas Diretrizes Curriculares Nacionais para os Cursos de Comunicação Social fixadas por meio da Resolução CNE/CES no 16/2002 - que indicava os Pareceres CNE/CES 492/2001 e 1.363/2001 para regulamentarem o Plano de Ensino -, e já destacavam a importância do equilíbrio entre a teoria da academia e a prática do mercado (CONSELHO NACIONAL DE 
EDUCAÇÃO, 2002).

Entretanto, o resultado eram aulas nas quais o processo ensino e aprendizagem deixava muito a desejar. Ao término do meu curso, o manuseio de uma câmera fotográfica digital single lens reflex DSLR - ainda era um campo obscuro. As teorias da fotografia se faziam claras, mas a parte prática das aulas não trouxe a bagagem necessária para a atuação no mercado de trabalho. Mas, por que o professor não conseguiu ensinar em sala? Ou então: por que eu não consegui aprender? Não houve interesse suficiente dos alunos ou o professor não conseguiu trazer os elementos necessários para que a teoria e a prática se fizessem claras e complementares no ensino do fotojornalismo?

Meditsch (2014) destaca que o tempo vivido em sala de aula, durante a graduação, não poderá ser suficiente diante de tantas habilidades que o mercado de trabalho exige dos profissionais.

Se é claro que o jornalista, como intelectual, necessita de uma sólida capacidade de interpretação e de uma ampla cultura geral - e aí quase todo o conhecimento acadêmico costuma ser útil - também é evidente que o curso de graduação tem duração limitada para lhe garantir o que só alcançará ao longo de muitos anos, num processo de formação permanente. Por isso, o projeto pedagógico precisa ser focado nos conteúdos acadêmicos que são imprescindíveis a um bacharel em jornalismo. (MEDITSCH, 2014, p. 1).

Mesmo assim, o debate sobre o equilíbrio se tornou válido diante do texto das novas Diretrizes Curriculares Nacionais, instituído por meio da Resolução ${ }^{0}$ 01/2013 do CNE/CES, que aponta em diversos trechos esta necessidade, destacando competências gerais, 
pragmáticas, cognitivas e comportamentais, dentro de seis eixos de fundamentação: humanística, específica, contextual, profissional, processual e laboratorial. A menção ao termo teoria e prática, e seus sinônimos, aparece em específico em alguns trechos da Resolução, como no inciso III do Artigo $1^{\circ}$, no inciso V do Artigo $3^{\circ}$, nos incisos I e III do Artigo $4^{\circ}$, no inciso III do Artigo $6^{\circ}$ e no caput do Artigo $9^{\circ}$ (CONSELHO NACIONAL DE EDUCAÇÃO, 2013).

Assim, chegou-se à pergunta "de que modo os professores de fotojornalismo percebem as novas Diretrizes Curriculares Nacionais?". Para respondê-la foi realizada uma pesquisa composta por quatro fases: o envio de questionário semi-estruturado aos professores de fotojornalismo, a categorização dos dados coletados, a inferência dos dados coletados com base em parâmetros extraídos do texto das novas DCNs e a interpretação final e aproximação dos resultados da pesquisa empírica com o problema inicial de pesquisa.

\section{Justificativa}

O texto das novas DCNs é resultado do Relatório da Comissão de Especialistas do MEC, instituída pela Portaria MECSESU 203/2009, que a partir da realização de um estudo sobre o ensino do jornalismo apresentou um texto detalhado, apontando as falhas históricas na estruturação curricular, incluindo uma proposta para as diretrizes e recomendações finais. Entre os pontos principais, a Comissão identificou a profunda ruptura entre as frentes teórica e prática no ensino, apontando uma situação onde a teoria da comunicação evolui desvinculada da prática profissional, enquanto 
o conteúdo profissional possuía característica "meramente técnica" (MELO et al., 2009, p. 12).

Para verificar a relevância do tema, um levantamento das produções acadêmicas acerca da temática da pesquisa, o ensino do fotojornalismo relacionado à teoria e a prática em sala de aula foi realizado. Trata-se de uma pesquisa breve do tipo "estado da arte" em bancos de teses com produções nacionais. Ferreira resume o tipo de pesquisa como:

[...] de caráter bibliográfico, elas parecem trazer em comum o desafio de mapear e de discutir uma certa produção acadêmica em diferentes campos do conhecimento, tentando responder que aspectos e dimensões vêm sendo destacados e privilegiados em diferentes épocas e lugares, de que formas e em que condições têm sido produzidas certas dissertações de mestrado, teses de doutorado, publicações em periódicos e comunicações em anais de congressos e de seminários. (FERREIRA, 2002, p. 256)

O caráter categorizante deste tipo de pesquisa não se aplicou ao trabalho realizado, visto que o objetivo era verificar a relevância do tema. Deste modo, o levantamento mostrou a quantidade de trabalhos e as lacunas existentes sobre o equilíbrio entre teoria e prática no ensino superior na área de comunicação, em especial, da disciplina do fotojornalismo.

Dentro da pesquisa, realizada nas plataformas Scielo, Capes/ CNPq e BDTD foram identificados 712 trabalhos com as palavras chaves delimitadas - as mesmas deste artigo - dos quais apenas sete estavam realmente relacionados ao tema proposto nesta pesquisa. $\mathrm{O}$ que mais chamou a atenção durante o levantamento foram os 
resultados para três combinações em especial, conforme tabela a seguir.

Tabela 1 - Ausência de resultados/menores resultados encontrados

\begin{tabular}{|l|c|c|c|}
\hline $\begin{array}{c}\text { ITEM } \\
\text { (COMBINAÇÃO PALAVRAS-CHAVE) }\end{array}$ & SCIELO & $\begin{array}{c}\text { CAPES/ } \\
\text { CNPQ }\end{array}$ & BDTD \\
\hline 4. Ensino superior e Fotojornalismo & 0 & 0 & 2 \\
\hline 7. Teoria e prática e Fotojornalismo & 0 & 0 & 0 \\
\hline 9. Currículo e Fotojornalismo & 0 & 0 & 0 \\
\hline
\end{tabular}

Fonte: A autora, 2016

A ausência de produções ao combinar as três palavras chaves Ensino superior, Teoria e prática e Currículo com a palavra, que representa o objeto principal da pesquisa: Fotojornalismo, demonstrou a relevância e a necessidade de se produzir mais debates acerca do tema. $O$ fato também é um indicativo para a falta de referências bibliográficas sobre o assunto, dificultando o acesso a autores e produções, tornando a pesquisa um verdadeiro desafio, mesmo considerando os resultados positivos encontrados nas demais combinações de palavras chaves.

\section{O processo da pesquisa}

Para o desenvolvimento da pesquisa, foram realizadas entrevistas com professores de fotojornalismo das Universidades públicas e privadas sem fins lucrativos dos estados do Paraná, Rio Grande do Sul e Santa Catarina, identificadas e selecionadas por meio do site do Ministério da Educação (BRASIL, 2015). As IESs públicas foram selecionadas por oferecerem ensino superior $100 \%$ 
100 A teoria versus a prática e as novas Diretrizes Curriculares Nacionais no ensino do fotojornalismo

gratuito, financiado pelos governos estaduais e federal.

As 33 Instituições de Ensino Superior da Região Sul do Brasil selecionadas para participarem da pesquisa foram Universidade Federal da Integração Latino-Americana (UNILA), Universidade Federal do Paraná (UFPR), Universidade Estadual de Londrina (UEL), Universidade Estadual de Maringá (UEM), Universidade Estadual de Ponta Grossa (UEPG), Universidade Estadual do Centro Oeste (Unicentro) e Pontifícia Universidade Católica do Paraná (PUCPR) no Paraná; Universidade Federal do Pampa (UNIPAMPA), Universidade Federal de Pelotas (UFPEL), Universidade Federal de Santa Maria (UFSM), Universidade Federal do Rio Grande (FURG), Universidade Federal do Rio Grande do Sul (UFRGS), Universidade de Caxias do Sul (UCS), Universidade do Vale do Rio dos Sinos (UNISINOS), Universidade Católica de Pelotas (UCPEL), Universidade de Passo Fundo (UPF), Pontifícia Universidade Católica do rio Grande do Sul (PUCRS), FEEVALE, Universidade de Santa Cruz do Sul (UNISC), Universidade Regional do Noroeste do Estado do Rio Grande do Sul (UNIJUÍ), Universidade da Região da Campanha (URCAMP), Universidade Regional Integrada do Alto Uruguai e das Missões (URI), Universidade de Cruz Alta (UNICRUZ), Universidade Luterana do Brasil (ULBRA), Centro Universitário Franciscano (UNIFRA), Centro Universitário Metodista (IPA) e Centro Universitário Univates (UNIVATES) no Rio Grande do Sul, e em Santa Catarina, Universidade Federal da Fronteira Sul (UFFS), Universidade Federal de Santa Catarina (UFSC), Universidade do Vale do Itajaí (UNIVALI), Universidade do Oeste de Santa Catarina (UNOESC), Universidade Comunitária da Região de Chapecó (UNOCHAPECÓ) e Universidade do Sul de 
Santa Catarina (UNISUL).

A pesquisa se dividiu em quatro etapas, sendo a primeira constituída por envio de questionário semi-estruturado às IESs, por meio de ferramenta online, direcionado aos professores de fotojornalismo. O questionário apresentou 36 perguntas referentes ao perfil profissional do docente, rotina de trabalho, didática e metodologia utilizadas em sala de aula, promoção de interdisciplinaridade, estrutura que a IES proporciona, e, por fim, ao conhecimento que o docente possui com relação às novas DCNs. Devido ao baixo índice inicial de respostas, promovemos o reenvio do questionário por seis vezes durante o período de 19 de maio e 30 de setembro de 2015, resultando em 17 respostas.

Durante a segunda fase foi feita a categorização dos dados obtidos de acordo com a metodologia de Bardin (1994, p. 95), com a leitura flutuante e uma descrição inicial, para identificar possíveis formatos de tratamento e inferência do material coletado, a partir de uma pré-análise. Para a categorização realizou-se a definição inicial de unidades de contexto, que são superiores às unidades de categoria, fazendo parte da codificação, com a classificação temática das palavras-chave feita com base no texto da Resolução $n^{0}$ 01/2013 - as novas DCNs - como elemento de referência na eleição destas palavras. (BARDIN, 1994, p. 15).

Considerando que o objetivo do estudo é verificar de que modo os professores percebem as diretrizes curriculares, a divisão das unidades de contexto foi feita da seguinte forma: Universo 1 : professores que conhecem as DCNs e acreditam no auxílio destas para a docência; Universo 2: professores que conhecem as DCNs, mas não sabem dizer como estas poderiam auxiliar no seu trabalho 
como docente; e Universo 3: professores que não conhecem/leram as DCNs.

As respostas do questionário foram divididas em unidades de registro, que, segundo Franco (2008, p. 41), constitui "a menor parte do conteúdo, cuja ocorrência é registrada de acordo com as categorias levantadas.”. Segundo a autora, as Unidades de Registro podem ser a palavra, o tema, o personagem ou o item. Ainda ao delimitar as unidades de registro é possível que se atinja mais precisão combinando dois ou mais termos, conforme destaca Franco (2008). Neste estudo, as unidades de registro são as palavras - ou termos, que são as palavras ligadas ao mesmo assunto, ou sinônimos.

$\mathrm{Na}$ terceira fase ocorreu a inferência dos dados coletados, com base em parâmetros extraídos do texto das novas DCNs, com o objetivo de mediar e promover uma transição entre a descrição inicial que se faz dos dados coletados, e a interpretação final dos resultados, conforme exemplifica Bardin (1994, p. 39).

Franco (2008) destaca que a inferência é o ato de comparar o material coletado, com o objetivo de superar a mera descrição dos resultados obtidos. Deste modo, o texto da Resolução n ${ }^{\circ}$ 01/2013 servirá de base comparativa para as respostas recebidas. Para a realização da inferência dos resultados da pesquisa, as categorias foram comparadas com o texto da Resolução n ${ }^{\circ}$ 01/2013, bem como com o Relatório da Comissão de Especialistas, que deu origem às novas DCNs.

Finalmente, a quarta e última fase corresponde à interpretação geral dos dados, obtidos após a inferência, e apresentação dos resultados. Neste momento retoma-se o debate a respeito das novas DCNs, com o objetivo de responder ao problema inicial de pesquisa, 
considerando os artigos destacados, bem como o restante do texto das Diretrizes e o Relatório da Comissão de Especialistas do MEC.

Para Franco (2008), as mensagens emitidas durante a entrevista, ou seja, as respostas dos professores, estão diretamente condicionadas pelo contexto em que eles estão inseridos. Deste modo, o contexto de cada professor foi considerado no momento da inferência dos dados.

\section{Os resultados obtidos}

Os 16 professores participantes da pesquisa foram divididos em três unidades de contexto: Universo 1: professores que conhecem as DCNs e acreditam no auxílio destas para a docência; Universo 2: professores que conhecem as DCNs, mas não sabem dizer como estas poderiam auxiliar no seu trabalho como docente; e Universo 3: professores que não conhecem/não leram as DCNs.

Tabela 2 - Unidades de contexto

\begin{tabular}{|l|l|l|}
\hline \multicolumn{1}{|c|}{ UNIVERSO 1 } & \multicolumn{1}{c|}{ UNIVERSO 2 } & \multicolumn{1}{c|}{ UNIVERSO 3 } \\
\hline PROFESSOR 4 & PROFESSOR 1 & PROFESSOR 10 \\
\hline PROFESSOR 5 & PROFESSOR 2 & PROFESSOR 11 \\
\hline PROFESSOR 6 & PROFESSOR 3 & PROFESSOR 12 \\
\hline PROFESSOR 7 & PROFESSOR 13 & PROFESSOR 16 \\
\hline PROFESSOR 8 & & \\
\hline PROFESSOR 9 & & \\
\hline PROFESSOR 14 & & \\
\hline PROFESSOR 15 & & \\
\hline
\end{tabular}

Fonte: A autora, 2016 
Dentro das unidades de contexto identificaremos nos itens seguintes as unidades de registro (A, B, C, D e assim por diante) referentes às categorias dos professores, promovendo $\mathrm{o}$ reagrupamento desses segundo os temas das perguntas, com base nas respostas fornecidas pelos professores nas perguntas abertas, conforme o quadro a seguir:

Quadro 1 - Unidades de registro e categoria correspondente

\begin{tabular}{|c|c|c|}
\hline TEMA & $\begin{array}{l}\text { UNIDADE DE } \\
\text { REGISTRO }\end{array}$ & CATEGORIA \\
\hline \multirow{3}{*}{1 - FORMAÇÃO } & $\mathrm{A}$ & Possui especialização na área; \\
\hline & $\mathrm{B}$ & Possui mestrado na área; \\
\hline & $\mathrm{C}$ & Possui doutorado na área; \\
\hline \multirow{2}{*}{$\begin{array}{l}2-\text { TEMPO DE } \\
\text { DOCENCIA }\end{array}$} & $\mathrm{D}$ & Até 9 anos; \\
\hline & $\mathrm{E}$ & 10 anos ou mais; \\
\hline \multirow{3}{*}{$\begin{array}{l}3 \text { - OCUPAÇÃO } \\
\text { PARALELA }\end{array}$} & $\mathrm{F}$ & $\begin{array}{l}\text { Professores com ocupação paralela ligada } \\
\text { à fotografia ou jornalismo; }\end{array}$ \\
\hline & G & $\begin{array}{l}\text { Professores que dão aula em mais de uma } \\
\text { IES; }\end{array}$ \\
\hline & $\mathrm{H}$ & $\begin{array}{l}\text { Professores com, pelo menos, três empre- } \\
\text { gos; }\end{array}$ \\
\hline \multirow{5}{*}{$\begin{array}{l}4-\text { TEORIA E } \\
\text { PRÁTICA }\end{array}$} & I & $\begin{array}{l}\text { Professores que mencionaram uso de ex- } \\
\text { periência profissional em sala de aula; }\end{array}$ \\
\hline & $\mathrm{J}$ & $\begin{array}{l}\text { Professores que mencionaram teoria e } \\
\text { prática espontaneamente em pergunta so- } \\
\text { bre metodologia e didática; }\end{array}$ \\
\hline & $\mathrm{K}$ & $\begin{array}{l}\text { Professores que acreditam promover o } \\
\text { equilíbrio teoria e prática (com exemplos } \\
\text { detalhados); }\end{array}$ \\
\hline & $\mathrm{L}$ & $\begin{array}{l}\text { Professores que exemplificam teoria e } \\
\text { prática como pauta e saída fotográfica; }\end{array}$ \\
\hline & M & $\begin{array}{l}\text { Professores que mencionam carga horária } \\
\text { como fator influenciador para o equilíbrio; }\end{array}$ \\
\hline
\end{tabular}




\begin{tabular}{|l|c|l|}
\hline \multirow{2}{*}{$\begin{array}{l}\text { 5 - INTERDIS- } \\
\text { DE }\end{array}$} & N & $\begin{array}{l}\text { Professores que acreditam promover a } \\
\text { interdisciplinaridade (com exemplos de- } \\
\text { talhados); }\end{array}$ \\
\cline { 2 - 3 } 6-ESTRUTURA & O & $\begin{array}{l}\text { Professores que não promovem a interdis- } \\
\text { ciplinaridade; }\end{array}$ \\
\cline { 2 - 3 } & $\mathrm{P}$ & $\begin{array}{l}\text { Professores satisfeitos com a estrutura la- } \\
\text { boratorial da IESs (lab. e equipamentos); }\end{array}$ \\
\hline \multirow{3}{*}{$\begin{array}{l}\text { 7-APRIMORA- } \\
\text { MENTO NA DO- } \\
\text { CÊNCIA }\end{array}$} & $\mathrm{R}$ & $\begin{array}{l}\text { Professores insatisfeitos com a estrutura } \\
\text { laboratorial da IESs (lab. e equipamen- } \\
\text { tos); }\end{array}$ \\
\cline { 2 - 3 } & $\mathrm{S}$ & $\begin{array}{l}\text { Professores que acreditam que podem me- } \\
\text { lhorar com base em condições pessoais; }\end{array}$ \\
\cline { 2 - 3 } & $\mathrm{T}$ & $\begin{array}{l}\text { Professores que acreditam que podem } \\
\text { melhorar com base em condições mistas } \\
\text { (pessoais e externas); }\end{array}$ \\
\hline
\end{tabular}

Fonte: A autora, 2016

A apresentação das categorias e universos delimitados, conforme o perfil identificado de cada participante da pesquisa, será feita nas três tabelas a seguir. O comparativo geral dos resultados e a inferência das respostas fornecidas para as questões abertas será feito após a apresentação das três tabelas de categorização dos universos 1, 2 e 3. A seguir, a tabela de Categorização do Universo 1, que deve ser analisada com base no Quadro 1, correspondente aos professores que conhecem as DCNs e acreditam no auxílio destas para a docência. 
Tabela 3 - Categorização universo 1

\begin{tabular}{|l|l|l|l|l|l|l|l|l|l|l|l|l|l|l|l|l|l|l|l|l|l|l|}
\hline \multicolumn{1}{|c|}{ TEMA } & \multicolumn{3}{|c|}{1} & \multicolumn{3}{|c|}{2} & \multicolumn{3}{|c|}{3} & \multicolumn{3}{|c|}{4} & \multicolumn{3}{|c|}{6} & \multicolumn{3}{c|}{7} \\
\hline CATEGORIA & $\mathrm{A}$ & $\mathrm{B}$ & $\mathrm{C}$ & $\mathrm{D}$ & $\mathrm{E}$ & $\mathrm{F}$ & $\mathrm{G}$ & $\mathrm{H}$ & $\mathrm{I}$ & $\mathrm{J}$ & $\mathrm{K}$ & $\mathrm{L}$ & $\mathrm{M}$ & $\mathrm{N}$ & $\mathrm{O}$ & $\mathrm{P}$ & $\mathrm{Q}$ & $\mathrm{R}$ & $\mathrm{S}$ & $\mathrm{T}$ \\
\hline Professor 4 & & $\mathrm{x}$ & & & $\mathrm{x}$ & $\mathrm{x}$ & & & & & & & & & & $\mathrm{x}$ & & & & $\mathrm{x}$ \\
\hline Professor 5 & & $\mathrm{x}$ & & & $\mathrm{x}$ & & & & $\mathrm{x}$ & $\mathrm{x}$ & $\mathrm{x}$ & & & $\mathrm{x}$ & & $\mathrm{x}$ & & $\mathrm{x}$ & & \\
\hline Professor 6 & & $\mathrm{x}$ & & $\mathrm{x}$ & & $\mathrm{x}$ & $\mathrm{x}$ & $\mathrm{x}$ & & $\mathrm{x}$ & & & & $\mathrm{x}$ & & $\mathrm{x}$ & & $\mathrm{x}$ & & \\
\hline Professor 7 & & & $\mathrm{x}$ & & $\mathrm{x}$ & $\mathrm{x}$ & & & & $\mathrm{x}$ & $\mathrm{x}$ & & & $\mathrm{x}$ & & $\mathrm{x}$ & & & $\mathrm{x}$ & \\
\hline Professor 8 & & $\mathrm{x}$ & & & $\mathrm{x}$ & $\mathrm{x}$ & & & & & $\mathrm{x}$ & & $\mathrm{x}$ & $\mathrm{x}$ & & $\mathrm{x}$ & & & $\mathrm{x}$ & \\
\hline Professor 9 & & $\mathrm{x}$ & & $\mathrm{x}$ & & & & & & & & & $\mathrm{x}$ & $\mathrm{x}$ & & & $\mathrm{x}$ & & $\mathrm{x}$ & \\
\hline Professor 14 & & $\mathrm{x}$ & & $\mathrm{x}$ & & $\mathrm{x}$ & & & & $\mathrm{x}$ & $\mathrm{x}$ & $\mathrm{x}$ & & & $\mathrm{x}$ & & $\mathrm{x}$ & & & $\mathrm{x}$ \\
\hline Professor 15 & & $\mathrm{x}$ & & $\mathrm{x}$ & & $\mathrm{x}$ & $\mathrm{x}$ & $\mathrm{x}$ & & $\mathrm{x}$ & $\mathrm{x}$ & & & $\mathrm{x}$ & & $\mathrm{x}$ & & $\mathrm{x}$ & & \\
\hline
\end{tabular}

Fonte: A autora, 2016

Passando para o grupo seguinte, temos a tabela de categorização do Universo 2, que mostra o perfil - balizado pelo Quadro 1 - dos professores que conhecem as DCNs, mas não sabem dizer como estas poderiam auxiliar no seu trabalho como docente.

Tabela 4 - Categorização universo 2

\begin{tabular}{|l|l|l|l|l|l|l|l|l|l|l|l|l|l|l|l|l|l|l|l|l|l|}
\hline \multicolumn{1}{|c|}{ TEMA } & \multicolumn{3}{|c|}{1} & \multicolumn{3}{|c|}{2} & \multicolumn{3}{|c|}{3} & \multicolumn{5}{|c|}{4} & \multicolumn{3}{|c|}{5} & \multicolumn{3}{|c|}{6} & \multicolumn{3}{c|}{7} \\
\hline CATEGORIA & A & B & C & D & E & F & G & H & I & J & K & L & M & N & O & P & Q & R & S & T \\
\hline Professor 1 & & & $\mathrm{x}$ & $\mathrm{x}$ & & & & & & $\mathrm{x}$ & & & & $\mathrm{x}$ & & & $\mathrm{x}$ & & & $\mathrm{x}$ \\
\hline Professor 2 & $\mathrm{x}$ & & & $\mathrm{x}$ & & $\mathrm{x}$ & $\mathrm{x}$ & $\mathrm{x}$ & $\mathrm{x}$ & $\mathrm{x}$ & $\mathrm{x}$ & $\mathrm{x}$ & & $\mathrm{x}$ & & $\mathrm{x}$ & & & $\mathrm{x}$ & \\
\hline Professor 3 & $\mathrm{x}$ & & & $\mathrm{x}$ & & $\mathrm{x}$ & & & $\mathrm{x}$ & $\mathrm{x}$ & $\mathrm{x}$ & $\mathrm{x}$ & & & $\mathrm{x}$ & $\mathrm{x}$ & & $\mathrm{x}$ & & \\
\hline Professor 13 & & & $\mathrm{x}$ & & $\mathrm{x}$ & $\mathrm{x}$ & & & & & & & $\mathrm{x}$ & $\mathrm{x}$ & & $\mathrm{x}$ & & & $\mathrm{x}$ & \\
\hline
\end{tabular}

Fonte: A autora, 2016

Prosseguindo para o Universo 3, temos a tabela de categorização que mostra o perfil dos professores que não conhecem ou não leram as DCNs - também de acordo com as categorias do Quadro 1 - e, por consequência, também não sabem de que modo elas podem auxiliar na sua atuação como docente. 
Tabela 5 - Categorização universo 3

\begin{tabular}{|l|l|l|l|l|l|l|l|l|l|l|l|l|l|l|l|l|l|l|l|l|}
\hline \multicolumn{1}{|c|}{ TEMA } & \multicolumn{3}{|c|}{1} & \multicolumn{3}{|c|}{2} & \multicolumn{3}{|c|}{3} & \multicolumn{1}{|c|}{4} & \multicolumn{3}{|c|}{5} & \multicolumn{3}{|c|}{6} & \multicolumn{3}{|c|}{7} \\
\hline CATEGORIA & $\mathrm{A}$ & $\mathrm{B}$ & $\mathrm{C}$ & $\mathrm{D}$ & $\mathrm{E}$ & $\mathrm{F}$ & $\mathrm{G}$ & $\mathrm{H}$ & $\mathrm{I}$ & $\mathrm{J}$ & $\mathrm{K}$ & $\mathrm{L}$ & $\mathrm{M}$ & $\mathrm{N}$ & $\mathrm{O}$ & $\mathrm{P}$ & $\mathrm{Q}$ & $\mathrm{R}$ & $\mathrm{S}$ & $\mathrm{T}$ \\
\hline Professor 10 & & $\mathrm{x}$ & & & $\mathrm{x}$ & $\mathrm{x}$ & & & & & $\mathrm{x}$ & & & $\mathrm{x}$ & & & $\mathrm{x}$ & $\mathrm{x}$ & & \\
\hline Professor 11 & & $\mathrm{x}$ & & $\mathrm{x}$ & & $\mathrm{x}$ & & & & & & & & $\mathrm{x}$ & & & $\mathrm{x}$ & & & \\
\hline Professor 12 & $\mathrm{x}$ & & & $\mathrm{x}$ & & $\mathrm{x}$ & & & & $\mathrm{x}$ & $\mathrm{x}$ & & $\mathrm{x}$ & $\mathrm{x}$ & & $\mathrm{x}$ & & $\mathrm{x}$ & & \\
\hline Professor 16 & & $\mathrm{x}$ & & & $\mathrm{x}$ & & & & $\mathrm{x}$ & $\mathrm{x}$ & $\mathrm{x}$ & & & $\mathrm{x}$ & & $\mathrm{x}$ & & $\mathrm{x}$ & & \\
\hline
\end{tabular}

Fonte: A autora, 2016

Resumindo o perfil levantado dos professores de fotojornalismo do Sul do País identificamos que estes são, em sua maioria, homens com mais de 40 anos. Apenas um dos participantes não possui formação base em Comunicação Social com habilitação em Jornalismo, sendo que pouco mais de um terço concluiu a graduação entre as décadas de 90 e 2000, enquanto outra parte igual de docentes, 37,5\%, concluiu entre 2001 e 2008.

Quanto à formação docente, verificamos que pouco mais da metade, 56,3\% possui apenas grau de mestrado, e entre eles, 92,3\% acredita que obteve nesta etapa bom preparo para exercício da docência. Entre os professores, 18,8\% possui apenas pós-graduação lato sensu, e os demais indicaram doutorado cursando, incompleto ou completo, além de um professor possuir pós-doutorado.

Dos 16 professores participantes, $12(68,9 \%)$ passaram por um curso de pós-graduação lato sensu e a maioria deles, 63,7\%, declarou que esta etapa da sua formação forneceu bom preparo para o exercício da docência.

Mais da metade dos respondentes $(56,2 \%)$ possui até 9 anos de atuação como docente, enquanto $43,8 \%$ possui 10 anos ou mais de experiência em sala de aula. Do total, 25\% já ultrapassaram os 15 anos de profissão e 10 possuem emprego paralelo ligado à fotografia, 
sendo que o percentual de professores que também atua em negócio próprio ou como fotógrafo em jornais é igual, 30\%. Os demais atuam como fotógrafos autônomos (20\%), em estúdio fotográfico $(10 \%)$ ou com a realização de projetos pessoais e consultorias $(10 \%)$.

Dos participantes, três possuem, pelo menos, três empregos, sendo que dois destes estão ligados à docência, enquanto a terceira ocupação está ligada à fotografia ou ao jornalismo. Deste modo, o tempo que o professor permanece em sala de aula é menor, sendo que a maioria dos professores passa até 12 horas por semana em sala (43,8\%), enquanto que para $37,5 \%$ dos docentes este tempo é de 16 a 20 horas semanais. Apenas 18,8\% passam de 30 a 40 horas por semana aula ministrando aulas.

Com relação à estrutura oferecida pela IES, no que diz respeito aos laboratórios, 68,8\% dos professores declararam estar satisfeitos com o ambiente oferecido pela instituição. Com relação aos equipamentos, o percentual é um pouco menor, 62,5\% estão satisfeitos com o material disponibilizado. Dos professores que afirmaram que a IES oferece estrutura laboratorial satisfatória, apenas um acredita que a IES não oferece equipamentos suficientes, no sentido de que a quantidade de câmeras oferecidas para uso em aula é insuficiente para a demanda de alunos por turma. Os professores que declararam que a IES não oferece estrutura laboratorial satisfatória também declararam que a universidade não oferece equipamentos que atendam à demanda.

Com relação a este dado, uma característica importante de ser ressaltada, é a de que os professores que se disseram insatisfeitos com a questão estrutural, incluindo laboratórios e equipamentos, são atuantes em universidades públicas, sendo duas estaduais 
(três professores) e duas federais (dois professores). O professor que declarou que o equipamento é de boa qualidade, porém em quantidade insuficiente, representa uma universidade pública. Os demais professores, que se disseram satisfeitos com a estrutura e os equipamentos, atuam todos em universidades privadas sem fins lucrativos. Deste modo podemos perceber que ainda existe uma defasagem na questão estrutural quando se trata da universidade pública.

Com relação às Novas Diretrizes Curriculares Nacionais, $75 \%$ dos participantes da pesquisa leu ou já conhece o texto, e destes, 4 não sabem dizer como o conteúdo apresentado na Resolução poderia auxiliar no seu trabalho como docente em sala de aula. E, ainda destes, apenas 2 não costumam orientar trabalhos de conclusão de curso. Não foi possível identificar de que modo os professores que afirmaram ter conhecimento do texto, o fizeram: se foi por incentivo ou imposição da IES, ou por iniciativa própria, visto que, infelizmente, tal pergunta não foi realizada durante o questionário. Deste modo, essa questão fica sugerida para novos estudos sobre o assunto, como um desdobramento, para se chegar a um entendimento mais aproximado com relação às motivações que levam os docentes ao contato com a legislação acerca dos cursos onde lecionam.

Resgatando a pergunta inicial proposta no problema de pesquisa, temos o seguinte questionamento: De que modo os professores de fotojornalismo percebem as novas Diretrizes Curriculares Nacionais? - para o qual teceremos agora algumas considerações com o objetivo principal de fornecer uma resposta, a partir da pesquisa realizada com os professores de fotojornalismo da Região Sul do Brasil. 
A partir dos dados coletados, percebemos que a grande maioria dos professores - 12 de 16 - declara conhecer as novas DCNs, e destes 12, oito as percebem como instrumento de orientação para seu desempenho em sala de aula, fornecendo para outras questões abertas respostas com palavras que demonstram e comprovam o conhecimento que eles possuem com relação às diretrizes.

Os professores que conhecem as DCNs e acreditam no auxílio delas para a docência são, em grande maioria, mestres, sendo que apenas um possui doutorado. Outra característica que se mostra comum dentro deste Universo 1, é de que apenas dois não atuam como fotógrafos profissionais, e outros dois possuem empregos paralelos não ligados à fotografia. Dois atuam em universidades públicas e estão insatisfeitos com a estrutura laboratorial e os equipamentos, e apenas um declarou não promover interdisciplinaridade. Com relação à experiência, apenas um professor possui até 4 anos de atuação como docente, três possuem entre 5 e 9 anos e também três possuem mais de 15 anos, enquanto um tem entre 10 e 15 anos de experiência como professor.

Como podemos perceber, o perfil dos professores do Universo 1 é bastante diversificado, exceto pela formação, cuja predominância é de mestres, e pela ocupação paralela. Temos nesta categoria uma grande variação de experiências, o que indica que o interesse no conhecimento das novas DCNs não depende da maturidade adquirida por meio da experiência. Também não existe modo de deduzir os motivos que levaram estes professores à leitura da Resolução, visto que pode ter sido motivada pela universidade onde ele atua, ou por vontade própria, indicando engajamento, ora da universidade, ora do professor. 
A pesquisa revelou que a carga horária dentro do Universo 1 é variada, sendo que dos 8 docentes, quatro atua mais de 18 horas por semana em sala de aula, com uma média de 27 horas aula por semana, enquanto os outros quatro possuem uma média de apenas seis horas aula e meia por semana, gerando uma média final no grupo de 16,75 horas aula por semana. Dada esta variação, percebemos que a carga horária não configura um fator que possa se dizer influenciador para que os professores tenham contato com as diretrizes, já que no Universo 1, estão os professores que conhecem e sabem como as DCNs podem auxiliar no seu exercício docente.

Destes 12 que conhecem as DCNs, quatro não souberam dizer de que forma as diretrizes poderiam auxiliar na sua atuação docente. Considerando que as respostas fornecidas por estes quatro professores (1, 2, 3 e 13) em outras questões abertas, podemos verificar que não existe uma sintonia muito grande dos seus discursos com as premissas apontadas no texto da Resolução $n^{0}$ 01/2013, levando a entender que, na realidade, eles podem não conhecer a fundo as diretrizes, e talvez tenham respondido que conheciam por outros motivos.

Neste grupo, o Universo 2, apenas um professor atua em universidade pública, e os docentes apresentaram carga horária de oito a 16 horas semanais. Dois possuem experiência de até 4 anos, um tem entre 5 e 9 anos, enquanto apenas um possui mais de 15 anos de atuação como docente. Dois dos professores possuem especialização, enquanto os outros dois possuem doutorado e pósdoutorado. Dos 4 professores, apenas um não atua como fotógrafo profissional, e também um possui emprego paralelo não ligado à fotografia. Também um professor descreve que não costuma 
promover a interdisciplinaridade, atribuindo a dificuldade ao fato de que os alunos não possuem equipamentos próprios, para que se possa desenvolver um trabalho em horário extra-aula.

Neste caso, poderíamos concluir que os professores do Universo 2 não possuem um engajamento profundo nas atividades da universidade, visto sua baixa carga horária semanal (uma média de 11 horas aula por semana), considerando que o tempo em que estes estão inseridos em sala não seria o suficiente para que eles sentissem a necessidade do apoio das novas DCNs. Entretanto já foi verificado dentro do Universo 1 - onde temos professores com mais de 18 horas e professores com apenas 2 horas aulas semanais - que o fator carga horária não caracteriza regra para o conhecimento das DCNs.

O fator interdisciplinaridade ligado aos equipamentos próprios, mencionado por um dos professores, demonstra um conhecimento superficial das diretrizes, já que a prática interdisciplinar não deve depender de questões pessoais dos alunos, sendo promovida dentro da universidade, com subsídios ofertados por esta e em um trabalho de cooperação entre os demais docentes da IES. O envolvimento com ocupações paralelas, adicionado à baixa carga horária, também poderia se tornar um indicativo de que o profissional estaria bastante engajado em questões externas à universidade, o que poderia fazer com que a atenção dedicada fosse menor, entretanto também verificamos no Universo 1 que os docentes apresentam ocupações paralelas, derrubando a ligação deste fator com o conhecimento das DCNs.

Por outro lado, os professores que declararam não conhecer as DCNs (10, 11, 12 e 16) demonstraram por meio de suas respostas 
nas demais questões, alguma sintonia com as premissas presentes na Resolução $n^{\circ} 01 / 2013$, apontando para a coerência que existe entre o que postula o texto normativo e as necessidades vividas em sala de aula. Deste modo, podemos perceber também que as novas DCNs acabam por trazer uma orientação que não foge ao que a maioria dos professores acredita ser o correto, remetendo ao debate descrito por Melo et al. (2009), a respeito de incluir no documento os anseios da comunidade docente.

Dentro deste grupo, o Universo 3, verificamos que dois dos professores possuem até 4 anos de experiência e os outros dois possuem de 10 a 15 anos de atuação na docência. Dois exercem sua função em universidades públicas, enquanto os outros dois atuam em IES privadas. Dos quatro professores, apenas um não possui ocupação paralela, e três deles ministram 16 horas aula semanalmente, enquanto um possui uma carga horária semanal de 40 horas. Apenas um participante declarou não promover a interdisciplinaridade, mas justificou que não houve oportunidade apenas pelo curto espaço de tempo que está atuando na IES.

Mais uma vez, ao verificar a carga horária, em comparação com os Universos 1 e 2, podemos perceber que o desconhecimento das novas DCNs não está necessariamente ligado ao engajamento do professores na IES, visto que a carga horária destes professores do Universo 3 também apresenta variações, incluindo professores com carga superior a 40 horas aula semanais, e ainda assim eles desconhecem o texto. Também verificamos que o contraste no tempo de experiência demonstra que o desconhecimento ou desinteresse por parte do professor com relação ao texto das diretrizes não é uma consequência de pouca experiência, ao mesmo tempo em que a 
extensa experiência não é um fator que pesa no sentido de promover o engajamento do profissional no sentido de conhecer as normas.

Entretanto, com base nas respostas, também verificamos que a dificuldade em equilibrar teoria e prática não se faz tão presente como nos debates apresentados ao longo do estudo. Podemos entender que, ao se sentir observado, o participante optou por declarar que promove a teoria e a prática, já que esta seria a premissa correta. Contudo, podemos relacionar esse fato às respostas fornecidas com menção espontânea sobre teoria e prática, já na primeira questão, o que nos mostra que, de fato, os professores acreditam que o equilíbrio entre as duas frentes é essencial para a qualidade das aulas.

Deste modo, verificamos que não existe claramente uma prerrogativa para que os professores conheçam ou não as Diretrizes. Os que possuem conhecimento com relação ao conteúdo da Resolução $n^{\circ}$ 01/2013, a percebem como normas de orientação e apoio ao professor, no sentido de garantir uma formação completa e homogênea, bem como um instrumento que garante ao aluno condições básicas que asseguram qualidade no Curso de Jornalismo.

Como corolário da pergunta inicial, que figurou o problema de pesquisa, "De que modo os professores de fotojornalismo percebem as novas Diretrizes Curriculares Nacionais para os Cursos de Jornalismo?”, fica a pergunta "E em que medida as DCNs afetam a atuação destes?", cuja resposta não pôde ser apresentada, visto que não foi possível ter certeza de que os professores possuem real conhecimento com relação ao texto das diretrizes.

Ao resgatar o debate travado ao longo deste trabalho, porém, podemos perceber que um possível motivo para o grande desconhecimento das DCNs seja o histórico de mudanças contínuas 
e, por vezes, superficiais, impostas de modo verticalizado que a educação superior no campo da Comunicação viveu nos últimos anos. Considerando ainda que na maioria dos casos os docentes não foram sequer ouvidos, no sentido de contribuir com seus anseios, este histórico pode ter formado uma legião de professores desacreditados de normativas, que ao pensarem no eterno "tira e põe" de que tratou Bernardo (2010), acabam por não crer que sejam diretrizes que permanecerão por muito tempo, não sendo, portanto, tão importantes de serem lidas, conhecidas.

\section{Considerações finais}

Depois de realizada a pesquisa e da mensuração dos dados, verificou-se que os resultados obtidos apontaram para um equilíbrio entre a quantidade de professores ainda pouco familiarizados com o texto das diretrizes e a quantidade de professores que já tiveram contato com a nova norma. Entretanto, pudemos perceber que os objetivos em sala de aula de ambos os grupos de professores não destoam de modo significativo do que postula a Resolução $n^{\circ}$ 01/2013.

Dentro de um contexto de contínuas mudanças e controvérsias, inclusive pautado por regulamentações que não se estabilizaram, muito menos conseguiram se estabelecer, parece lógico o não conhecimento ou o não interesse específico por parte dos docentes pelas DCNs atuais. Ainda aqueles que destacaram ter lido, mas não demonstraram real conhecimento das diretrizes, podem ter agido desta maneira por motivos diversos, entre os quais estariam a 
vergonha de desconhecer a legislação que vigora sobre sua profissão e o medo de ser julgado, o que torna a situação ainda pior, do ponto de vista da responsabilidade da docência.

Por outro lado, percebemos uma espécie de "já visto/ já escutado/já falado" por parte dos professores, pois cada nova legislação implementada é justamente uma repetição destas legislações anteriores que acabaram por não se estabelecer, o que faz com que os professores estejam cansados de tantas e sempre tão pouco inovadoras mudanças, que apresentam os mesmos motes, como teoria e prática e outros valores já debatidos. Deste modo os docentes acabam por dizer que já conhecem as novas DCNs, ao mesmo tempo em que eles não possuem uma real vontade de estar em contato direto com o material por julgar ser apenas mais uma entre tantas legislações fracassadas. Por este motivo é que temos como resultado o aspecto de indiferença nos demais aspectos, como carga horária do docente, experiência e etc., pois independente de como é sua rotina de trabalho em sala de aula, a legislação se tornou apenas uma regra a ser seguida, para a qual não existe fiscalização, a não ser o rendimento do aluno.

Este desequilíbrio entre teoria e prática apresentado tanto no relatório da Comissão de Especialistas, quanto em debates anteriores sobre o ensino de jornalismo, parece estar muito mais presente no debate teórico do que na prática docente. Isto porque, no momento em que se verifica os dados coletados por meio da entrevista com os professores de fotojornalismo, a grande maioria se diz tentar - e conseguir, na medida do possível -, promover determinado equilíbrio de acordo com o que julgam ser esta prática pedagógica, incluindo os professores que não conhecem o texto da Resolução no 01/2013. 
Com relação aos professores que disseram conhecer as DCNs, mas que mesmo assim não sabem como elas poderiam auxiliar no seu trabalho como docente, fica a dúvida - e até uma sugestão para novos estudos - a respeito dos motivos que levam estes professores a responder deste modo a pesquisa. Conforme já mencionado, uma hipótese que surge, neste momento, pode ser: estariam eles, na realidade, envergonhados por não conhecerem as diretrizes - o que fez com que dissessem que conheciam sem conhecer realmente, ou eles perderam o interesse depois de tantas mudanças ineficazes ao longo da história do ensino de Jornalismo?

Apesar da preocupação que cerca o fato de que uma boa parcela dos participantes da pesquisa desconhece o novo texto normativo, verificamos que, sim, na realidade a maioria deles procura promover a interdisciplinaridade e o equilíbrio entre a teoria e a prática em sala de aula, demonstrando que o documento aponta para a instauração de formatos já almejados pela comunidade docente em sala de aula.

Se as IESs vão conseguir seguir as novas premissas das Diretrizes Curriculares Nacionais, ainda é uma questão obscura, e pode servir de objeto de novas pesquisas. $\mathrm{O}$ que pudemos verificar até o momento, com certa clareza, é que as novas DCNs ainda não estão fazendo parte efetiva e claramente, do exercício do professor em sala de aula, bem como projeta situações ideais em ambientes que, em alguns casos, não estão preparados estruturalmente para atender a tais objetivos. Entretanto, a sintonia entre os preceitos apontados no texto e as premissas demonstradas pelos professores para sua docência levam a concluir que as DCNs, quando efetivamente implementadas, não representarão obstáculo, e sim elemento balizador para que os objetivos com relação à qualidade no ensino 
118 A teoria versus a prática e as novas Diretrizes Curriculares Nacionais no ensino do fotojornalismo

do jornalismo - e dos fotojornalistas - sejam atingidos.

\section{Referências}

BARDIN, Laurence. Análise de conteúdo. Lisboa: Edições 70, 1994.

BERNARDO, Cristiane Hengler Corrêa. Educação jornalística: entre a cruz da academia e a espada do mercado, 2010. Tese (Doutorado) - Universidade Federal do Mato Grosso do Sul, Campo Grande.

BRASIL. Ministério da Educação. Instituições de educação superior e cursos cadastrados. Brasília, DF: MEC, 2015. Disponível em: http://emec.mec.gov.br/. Acesso em: 18 maio 2015.

CONSELHO NACIONAL DE EDUCAÇÃO. Resolução CNE/ CES 16, de13 de março de 2002. Estabelece as Diretrizes Curriculares para a área de Comunicação Social e suas habilitações. Brasília, DF: CNE, 2002. Disponível em: http://portal.mec.gov.br/cne/ arquivos/pdf/CES162002.pdf. Acesso em: 18 maio 2015.

\section{CONSELHO NACIONAL DE EDUCAÇÃO. Resolução n ${ }^{\mathbf{0}} \mathbf{1}$, de $\mathbf{2 7}$} de setembro de 2013. Institui as Diretrizes Curriculares Nacionais para o curso de graduação em Jornalismo, bacharelado, e dá outras providências. Brasília, DF: CNE, 2013. Disponível em: http://portal.mec.gov.br/index.php?option=com_docman\&view=download\&alias=14242-rces001-13\&category_slug=setembro-2013-pdf\&Itemid=30192. Acesso em: 5 maio2015.

FERREIRA, Norma Sandra de Almeida. As pesquisas denominadas "estado da arte". Educação \& Sociedade, Campinas, SP, v. 23, n. 79, p. 257-272, 2002.

FRANCO, Maria Laura P. B. Análise de conteúdo. 3. ed. Brasília: Liber Livro Editora, 2008. (Série Pesquisa, v. 6). 
MEDITSCH, Eduardo. Oportunidade para o reencontro entre teoria e prática. Observatório da Imprensa, São Paulo, n. 787, 25 fev. 2014. Disponível em: http://observatoriodaimprensa.com.br/interesse-publico/_ed787_oportunidade_para_o_reencontro_entre_teoria_e_pratica/. Acesso em: 25 nov. 2015.

MELO, José Marques; PEREIRA JUNIOR, Alfredo Eurico Vizeu; MEDITSCH, Eduardo Barreto Vianna; ARAÚJO, Lucia Maria; CHAPARRO, Manuel Carlos da Conceição; MATTOS, Sergio Augusto Soares; MOREIRA, Sonia Virginia. Diretrizes curriculares nacionais para o curso de jornalismo. Relatório da Comissão de Especialistas instituída pelo Ministério da Educação (Portaria $\mathrm{N}^{\mathrm{o}}$ 203/2009, de 12 de fevereiro de 2009). Brasília, DF: MEC, 2009. Disponível em: portal.mec.gov.br/dmdocuments/documento_final_ cursos_jornalismo.pdf. Acesso em: 12 dez. 2014. 